\title{
Assessing the effect of fish size on species distribution model performance in southern Chilean rivers
}

\author{
Daniel Zamorano ${ }^{1,2}$, Fabio Abel Labra ${ }^{1,3}$, Marcelo Villarroel ${ }^{2}$, Shaw Lacy ${ }^{4}$, Luca Mao ${ }^{5,6}$, Marcelo Olivares ${ }^{7,8}$, \\ Matías Peredo-Parada ${ }^{\text {Corresp. } 2}$ \\ ${ }^{1}$ Centro de Investigación e Innovación en Cambio Climático, Facultad de Ciencias, Universidad Santo Tomás, Santiago, Chile \\ 2 Plataforma de Investigación en Ecohidrología y Ecohidráulica Limitada, Santiago, Chile \\ 3 Programa de Doctorado en Conservación y Gestión de la Biodiversidad, Facultad de Ciencias, Universidad Santo Tomás, Santiago, Chile \\ 4 The School for Field Studies, Center for Climate Studies, Puerto Natales, Chile \\ 5 Instituto de Geografía, Pontificia Universidad Católica de Chile, Santiago, Chile \\ 6 School of Geography, College of Science, University of Lincoln, Lincoln, United Kingdom \\ 7 Departamento de Ingeniería Civil, Universidad de Chile, Santiago, Chile \\ 8 Centro de Energía, Universidad de Chile, Santiago, Chile \\ Corresponding Author: Matías Peredo-Parada \\ Email address: matias.peredo@ecohyd.com
}

Despite its theoretical relationship, the effect of body size on the performance of species distribution models (SDM) has only been assessed in a few studies, and to date, the evidence shows unclear results. In this context, Chilean fishes provide an ideal case to evaluate this relationship due to their short size (fishes between $5 \mathrm{~cm}$ and $40 \mathrm{~cm}$ ) and conservation status, providing evidence for species at the lower end of the worldwide fish size distribution and representing a relevant management tool for species conservation. We assessed the effect of body size on the performance of SDM in nine Chilean river fishes, considering the number of records, performance metrics, and predictor importance. The study was developed in the Bueno and Valdivia basins of southern Chile. We used a neural network modeling algorithm, training models with a cross-validation scheme. The effect of fish size on selected metrics was assessed using linear models and beta regressions. While no relationship between fish size and the number of presences was found, our results indicate that the model specificity increases with fish size. Additionally, the predictive importance of Riparian Vegetation and Within-Channel Structures variables decreases for larger species. Our results suggest that the relationship between the grain of the dataset and the home range of the species could bias SDM, leading in our case, to overprediction of absences. We also suggest that evolutionary adaptation to low slopes among Chilean fishes increases the relevance of riparian vegetation in the SDMs of smaller species. This study provides evidence on how species size may bias SDM, which could potentially be corrected by adjusting the model grain. 
1

2

3

4

5

6

\section{Assessing the effect of fish size on species distribution model performance in southern Chilean rivers}

Daniel Zamorano ${ }^{1,2}$, Fabio Abel Labra ${ }^{1,3}$, Marcelo Villarroel2 ${ }^{2}$, Shaw Lacy ${ }^{4}$, Luca Mao ${ }^{5,6}$, Marcelo Olivares 7,8

\& Matías Peredo-Parada*2

1.- Centro de Investigación e Innovación para el Cambio Climático, Facultad de Ciencias, Universidad Santo Tomás

2.- Plataforma de Investigación en Ecohidrología y Ecohidráulica Limitada, Santiago, Chile.

3.- Programa de Doctorado en Conservación y Gestión de la Biodiversidad, Facultad de Ciencias, Universidad Santo Tomás, Santiago, Chile.

4.- Center for Climate Studies, The School for Field Studies, Puerto Natales, Chile

5.- School of Geography, College of Science, University of Lincoln, Lincoln, United Kingdom

6.- Instituto de Geografía, Pontificia Universidad Católica de Chile, Santiago, Chile

7.- Departamento de Ingeniería Civil, Universidad de Chile, Santiago, Chile.

8.- Centro de Energía, Universidad de Chile, Santiago, Chile.

* Corresponding Author (matias.peredo@ecohyd.com)

KEYWORDS

Neural networks, Chilean fishes, Anthropogenic variables, Specificity, Riparian vegetation, Structures within the channel. 


\section{ABSTRACT}

23 Despite its theoretical relationship, the effect of body size on the performance of species distribution models (SDM) has only been assessed in a few studies, and to date, the evidence shows unclear results. In this context, Chilean fishes provide an ideal case to evaluate this relationship due to their short size (fishes between $5 \mathrm{~cm}$ and $40 \mathrm{~cm}$ ) and conservation status, providing evidence for species at the lower end of the worldwide fish size distribution and representing a relevant management tool for species conservation. We assessed the effect of body size on the performance of SDM in nine Chilean river fishes, considering the number of records, performance metrics, and predictor importance. The study was developed in the Bueno and Valdivia basins of southern Chile. We used a neural network modeling algorithm, training models with a cross-validation scheme. The effect of fish size on selected metrics was assessed using linear models and beta regressions. While no relationship between fish size and the number of presences was found, our results indicate that the model specificity increases with fish size. Additionally, the predictive importance of Riparian Vegetation and Within-channel structures variables decreases for larger species. Our results suggest that the relationship between the grain of the dataset and the home range of the species could bias SDM, leading in our case, to overprediction of absences. We also suggest that evolutionary adaptation to low slopes among Chilean fishes increases the relevance of riparian vegetation in the SDMs of smaller species. This study provides evidence on how species size may bias SDM, which could potentially be corrected by adjusting the model grain. 


\section{INTRODUCTION}

42 Species distribution models (SDM) provide an important management tool to support conservation

43 planning. SDMs generate species distribution maps that allow for more efficient and effective field

44 inventories, suggest sites of high potential occurrence of rare species for survey planning, and permit

45 the testing of biogeographical, ecological and evolutionary hypotheses (Guisan \& Thuiller, 2005). Given

46 these advantages, different international organizations (e.g., UNEP, Conservation International, IUCN,

47 WWF) have employed SDM to address key policy objectives at a global scale (Cayuela et al., 2009).

Different species traits have been shown to influence species model performance (Brotons et al., 2004;

Segurado \& Araújo, 2004; McPherson \& Jetz, 2007; França \& Cabral, 2016), which could generate biases

in the SDM predictions made by each species, negatively impacting the its role as a management tool.

One important trait is body size (Radinger et al., 2017), which may affect SDM performance or accuracy

in different ways (McPherson \& Jetz, 2007). Small species are often less visible and harder to capture, reducing presence/absence data availability (McPherson \& Jetz, 2007) and implying less precise SDMs size, and home range may also affect SDM performance. Species with different home range sizes may perceive the environment of different way (McPherson \& Jetz, 2007). As a result, model performance is expected to be higher for species whose homerange matches the climatic or environmental data used to train the SDM (Suarez-Seoane, Osborne \& Alonso, 2002).

The relationship between body size, geographic range size, and home range in fish species may also affect SDM variable selection. For example, larger fishes can disperse farther than small fishes and are expected to be more significantly restricted by in stream barriers (Radinger \& Wolter, 2015; Radinger et 
63

64

65

anthropogenic drivers (Radinger \& Wolter, 2015; Radinger et al., 2017). Thus, body size can potentially affect SDMs by influencing predictor variable selection.

To date, the effect of body size on distribution models has been tested in different taxa with unclear results (e.g., M. McPherson \& Jetz, 2007; França \& Cabral, 2016; Morán-Ordóñez et al., 2017; Radinger et al., 2017). In the case of fish, this relationship has been tested indirectly for riverine fish (Radinger et al., 2017) and directly for marine and estuary fishes (Perry et al., 2005; França \& Cabral, 2016). For example, Radinger et al. (2017) tested future distributions according the body size of river fishes and showed that smaller-body fishes are less sensitive to anthropogenic intervention in the river network due to their smaller home ranges.

The native ichthyofauna in Chile comprises a total of 44 species, including two lampreys (Habit, Dyer \& Vila, 2006) and is characterized as being highly endemic, adapted to low slope rivers, and having small body sizes (Vila, Fuentes \& Contreras, 1999; Vila et al., 2006; Habit, Dyer \& Vila, 2006). In addition to its high biogeographic value, the Chilean ichthyofauna is broadly endangered, with only two species (Cheirodon austral Eigenmann, 1927 and Mugil cephalus Linnaeus, 1758) currently classified as non endangered, which provides additional modeling challenges. For example, all species have scant distribution data due to the type of research conducted in the area, and adult body size ranges from 5 to $40 \mathrm{~cm}$, making them additionally difficult to capture and sample. Given these challenges, assessing how fish size affects SDMs in Chile will allow us to determine better model methodologies suited to the region's small-sized, data-deficient and endangered species.

Our aim is to evaluate the relationship between fish size and SDM goodness-of-fit using three approaches: (1) assess the relationship between fish size and data availability, (2) assess the relationship between fish size and model performance, and (3) compare predictor variable participation and patterns 
85 86

87

88

according to fish size. We focus on two well-studied southern Chilean river basins, Bueno and Valdivia, and model nine native species.

\section{METHODS}

\section{Study area and modeled species}

The study area covers the Valdivia and the Bueno River basins located in the southern zone of Chile between $39.33^{\circ}$ and $41.08^{\circ} \mathrm{S}$ (Figure 1). The Valdivia River basin has a pluvial hydrological regime and is characterized by a chain of interconnected lakes at higher altitudes. The upper section of the Bueno River basin has a pluvio-nival regime, while the middle and lower parts of the basin are governed by a pluvial regime (Errázuriz K. et al., 1998).

Our study examined nine native freshwater fish species (Table 1): Aplochiton taeniatus Jenyns, 1842, Aplochiton zebra Jenyns, 1842, Basilichthys microlepidotus (Jenyns, 1841), Brachygalaxias bullocki (Regan, 1908), Cheirodon australe, Diplomystes camposensis Arratia, 1987, Galaxias maculatus (Jenyns, 1842), Percilia gillissi Girard, 1855, and Trichomycterus areolatus (Valenciennes in Cuvier \& Valenciennes, 1840). Statistical analyses of the effect of body size were carried out using theoretical species maximum length, which is available for all these species. Maximum length estimates were obtained from official species descriptions provided the conservation assessment of each species, developed by the Chilean Ministry of the Environment, with the only exceptions being B. bullocki and $B$. australis (Table 1).

\section{Modeling methods}

Model grain

To build the SDM database, the drainage network of the study area was divided into segments. We considered river segments as having homogeneous hydromorphological conditions with no significant 
107 confluences and 2 and $10 \mathrm{~km}$ in length. Each segment represented an analysis unit in which the

108 presence and SDM predictor variables for each species were evaluated. This segment definition was

109 generated using cartographic information, visual interpretation of Google Earth imagery (Google inc,

110 2009), and Arc GIS version 9.2 (ESRI, 2010). To characterize a set of hydrological variables for the study

111 area, we used the national official drainage network generated by the Military Geographic Institute

112 (Instituto GeográficoMilitar, Government of Chile).

\section{Species occurrence data}

114 Historical records of the georeferenced presences of the study species were obtained from the Ministry 115 of the Environment's (Ministerio del Medio Ambiente, Government of Chile) database on freshwater 116 organisms. This database was generated by collecting published databases of scientific samples in the 117 study area (Ministerio de Energía -División de Desarrollo Sustentable, 2016). Since this biogeographic 118 region contains 16 native fish species (Habit, Dyer \& Vila, 2006), our study accounts for 56\% of extant 119 species in this region of Chile (Vila et al., 2006). The remaining species had insufficient numbers of 120 occurrence records inthe database (between 0 and 10) and were not considered.

121 A field sampling campaign was conducted in the study area to increase the records by specie presents in 122 the government data. The sampling was performed in December 2015 and January 2016 using 123 electrofishing equipment (SAMUS, model 745G). We collected all fish along a 100 meter section of river, 124 with sampling times of 45 to $60 \mathrm{~min}$, depending on the hydromorphological features of the site. Seven 125 rivers were sampling: Llancahue River, Pinchichirre River, Nilfe Channel, Quinchilca River, Los Nadis

126 River, Punahue Channel and Cahuinalhue River, recording nine presences to seven species. All collected

127 fish were identified to species level. The electrofishing was approved by the National Fisheries Service, 128 permit number 514. 
129 Each presence record was associated with the closest river segment in the GIS, thus building a presence

130 database for species distribution modeling. Overall, 118 river segments had at least one presence

131 record. The total number of presences for each species across the two study basins ranged between 22

132 and 72 , but the modeling only considered one record per segment, so modeled presences ranged

133 between 14 and 36 (Table 1).

\section{Predictor variables}

135 The predictor variables or features considered were accumulated rainfall, catchment area, source-of-

136 flow, altitude, slope, channel width, percent riparian vegetation, land-use, cross-channel structures, and

137 within-channel structures (Table 2).

138 Annual rainfall was obtainedby relating the isolines of average annual rainfall (Dirección General de

139 Aguas, Government of Chile) over the segment basin. The catchment area was calculated using a $1 \mathrm{~km} \times$

$1401 \mathrm{~km}$ DEM image (Landsat 7 images from 2015, https://landsat.usgs.gov/) using the Hydrology package

141 in ArcGIS for each segment basin considering the accumulated catchment area. Source-of-flow, that

142 represents the geographical origin of the flow, was obtained and adapted from the published REC-Chile

143 classification (Peredo-Parada et al., 2011), and each category was used independently as a Boolean

144 variable. Final source-of-flow variables were lakes, floodplains, valleys and mountains. Altitude and

145 slope were estimated using the altitudes atthe downstream end of each river segment based on the

146 DEM. Channel width, riparian vegetation cover, land-use, cross-channel structures, and within-channel

147 structures were estimated using a visual analysis of Google Earth imagery. The channel width was

148 calculated as the mean of three points along the reach. Riparian vegetation coverage was considered up

149 to $50 \mathrm{~m}$ from the stream, with sections and land-use classes defined based on evaluation up to $200 \mathrm{~m}$.

150 Land use was defined in three categories: Antr-Antr $=$ on both banks over $50 \%$ of the area has

151 anthropogenic interventions; Nat-Antr = on one bank over $50 \%$ of the area has anthropogenic 
152 interventions; and Nat-Nat = on both banks less than $50 \%$ of the area has anthropogenic interventions.

153 Within-channel structures included roads parallel to the river, bank reinforcement, river channel

154 maintenance structures, and channelization, among others. Cross-channel structures included bridges,

155 dams, and water-intake structures.

156 Model training and evaluation

157 We used neural network (NNET) algorithms to estimate SDMs (Stern, 1996). This method was chosen

158 based on their good performance with presence and absence or pseudoabsencesfor species-distribution

159 data (Mastrorillo et al., 1997; Elith \& Leathwick, 2009). NNET is derived from a simple model that mimics

160 the structure and function of the brain and maximizes the prediction during the model-training phase by

161 comparing actual outputs with desired outputs (Manel, Dias \& Ormerod, 1999). All analyses were

162 performed in R (v 3.5.0) using the Caret package (Kuhn, 2008).

163 Models were trained using a 3- or 2-fold cross-validation scheme, according to records by species (Table

164 1). Pseudoabsences were set at twice the number of observed species presences and were randomly

165 selected. We designated as the final model the ensemble average of each k-fold model by its weighting

166 each individual model by their Area Under the Curve statistic (AUC) of the Receiver Operating 167 Characteristic (ROC).

168 The Caret R package was used to fit NNET models and tune the model's two hyperparameters, namely,

169 the weight decay for successive neural layers ("decay") and the number of hidden units ("size"). The grid

170 search procedure examined weight decay values ranging between 4 and 6 , while the number of hidden

171 units was allowed to vary between 0.05 and 0.9 . Both hyperparameter ranges were calibrated by a trial

172 and error process, optimizing the model performance.

173 Occurrence probabilities were categorized as presence/absence for all models. Thresholds were

174 determined to maximize the sum of sensitivity and specificity (MaxSens+Spec; PresenceAbsence 
175 package in $\mathrm{R} \vee 3.5 .0)(\mathrm{R}$ Core Team, 2017). This criterion is independent of the theoretical prevalence

176 (Manel, Dias \& Ormerod, 1999; Allouche, Tsoar \& Kadmon, 2006), causing the distribution of rare

177 species to be overpredicted. In our case, the theoretical prevalence in the study area for all the species

178 is close to 0.5 , but the presence of our study species is low, requiring a relaxation of this criterion when

179 defining the threshold that allows for the definition of each of the species distribution across the studied

180 watersheds. All the presences and environmental data by river segment in supplemental material

181 (Appendix S1).

\section{Relationship between fish size and models}

As proxy of body size, $\log _{10}$-transformations of maximum length (max. length) were calculated for each species. We assessed the relationship between max. length and the number of historical records in both basins, with balanced accuracy, sensitivity, specificity, true skill statistic (TSS), and area under curve (AUC), all different performance metrics (Altman \& Bland, 1994; Allouche, Tsoar \& Kadmon, 2006; Velez et al., 2007; Kuhn, 2008), and with variable importance to each predictor variable. Sensitivity evaluates the proportion of actual presences that are correctly classified and specificity evaluates the proportion of actual negatives that are correctly identified (Allouche, Tsoar \& Kadmon, 2006). AUC, TSS and balanced accuracy evaluate overall performance using different approximations, being valuable contrast them all (Velez et al., 2007; Kuhn, 2008). In all this cases, obtain a value of 1 to this metrics represent the best performance, and in the AUC case, 0.5 represent the worst performance. Variable importance is calculated with "Weights" method (Gevrey, Dimopoulos \& Lek, 2003), and the highest importance is 100.

The statistical test of the relationship between max. length and historical records was a classical linear model $(I m)$ (Chambers, 1992), while the other comparisons were evaluated with beta regression analysis (betareg) (Cribari-Neto \& Zeileis, 2010). This test assumes response variables to be in the standard unit 
198 interval $(0,1)$ and to be beta distributed, and it is more precise in performance metrics cases or variable

199 importance cases where the values are at a fixed interval. Rescaled Moment test (RMtest) and Q-Q plots

200 were applied to all residual models to evaluate model validity (Das \& Imon, 2016; Kozak \& Piepho,

201 2018). While, the normality test is used on observed data to evaluate parametricity, in regressions the

202 true errors are unobserved, being a common practice to use residuals as substitutes for observed data in

203 tests for normality (Das \& Imon, 2016). In this context, we used RMtest to evaluate normality of

204 residuals and validate betareg and Im models. RM test correct shrinkage and superimposed normality

205 effect of the residual data, improve its normality evaluation (Imon, 2003; Rana, Midi \& Imon, 2009).

206 To avoid a potential bias from conservation status by specie on all statistical tests, we introduced this 207 category as a covariable. Given the hierarchical relationship between conservation status categories, we 208 transformed this to a numeric covariable, with Least Concern (LC) being 1, Vulnerable (VU) as 2, and 209 Endangered (EN) as 3. Finally, an a priori betareg test was developed to discard the relationship 210 between the number of presences by model and metric performance models, allowing for directly 211 linking fish size with model indicators.

\section{RESULTS}

213 All models showed good performance, with ROC AUC varying between 0.82 and 0.98 , while TSS varied

214 between 0.45 and 0.83 . The best trained model was for $B$. australis (AUC $=0.98$ and TSS $=0.83$ ), while

215 the worst trained model was for $T$. areolatus (AUC $=0.82$ and TSS $=0.46$ ) (Table 1 ). The number of

216 presences used by the model did not show a significant relationship with model performance metrics

217 (betareg to AUC, $\mathrm{p}$ value $=0.104$, betareg to TSS, $\mathrm{p}$ value $=0.159$ )

218 Channel width and Catchment area were the most important variables in most species models,

219 excluding A. taeniatus, G. maculatus, and P. gillissi models, where Annual rainfall, Land-use: Antr-Antr,

220 and Altitude were the most important, respectively. However, if we added the Source-of-Flow 
221 participation by category, its participation was more relevant than the Channel width and Catchment

222 area for all species (Table 2).

\section{Historical records}

224 The number of presences and conservation status did not correlate with fish size (Im test: Conservation

225 status, coefficient $=-4.7$, std. error $=7.9, \mathrm{t}$ value $=-0.56, \mathrm{p}$ value $=0.57$; Historical records, coefficient $=-$ 8.1$, std. error $=9.67, \mathrm{t}$ value $=-0.84, \mathrm{p}$ value $=0.43)$. Model residuals show a normal distribution $($ Chisq $=$

$1.83, \mathrm{p}$ value $=0.59)$. The species with the lowest presence was $A$. zebra, with 22 records and $28 \mathrm{~cm}$

maximum length and is one of the largest native species found in the basins. The species with most

historical records was $T$. areolatus, with 72 presences and a maximum length of $15 \mathrm{~cm}$. However, many

of the $T$. areolatus presences were spatially clustered, and the model was trained using only 36 presence records (Table 1).

\section{2}

233

234

235

236

237

238

239

\section{Metric performance}

Of all the evaluated performance metrics, only specificity showed a significant positive relationship with fish size (Figure 2). In most modeled species, we observed residuals being normally distributed considering Q-Q plots and RMtest (Table 3). The only one exception is Source-of-flow: Mountains, with a non significant RMtest. Specificity had a positive relationship with fish size (Figure 2). Other metrics did not show significant relationships with fish size (Table 3).

\section{Variable importance}

When we examined the significance of individual predictor variables, we observed that only Riparian Vegetation and Within-Channel Structures showed a significant relationship with fish size. Again, we observed residuals being normally distributed, thus validating the statistical analysis (Table 3 ). In these cases, the fitted models for larger fish tended to give less importance to these variables than models for 
243 small fish, showing a negative relationship (Figure 2). Other variables did not show significant

244 relationships with fish size (Table 3).

245 When exploring the relationship between occurrence probability by SDM and percentage of Riparian

246 Vegetation and number of Within-Channel Structures (Figure 3), we found no clear patterns. In the

247 Riparian Vegetation case, smaller species tended to increase occurrence probability on reaches with less

248 riparian vegetation, but the pattern of larger species was unclear. In contrast, larger species tended to

249 show higher occurrence probabilities on reaches without Within-Channel Structures, while there was no

250 clear pattern in smaller fish species.

\section{DISCUSSION}

252 The principal result in the current study showed that SDM of smaller fishes has lower specificity, tending

253 to overpredict presences. This finding has important implications for conservation, management and the

254 science related to SDMs, especially in countries as Chile, with particularly small species. While, it is not

255 recommended modeling a group of species with the same methodology, is very common in papers and

256 management projects. In this context, our results show the relevance of evaluate potential bias

257 according to physiological and ecological traits by specie, identifying species that need different

258 methodologies to make more accurate model.

259 The good performance obtained for all the trained models shows how the hyperparametrization process

260 using software such as Caret allows us to obtain good SDMs (Kuhn, 2008). Additionally, good SDM

261 performance using few presences may also occur when models are projected on regions that have

262 highly similar environmental conditions to where the species occur (Pearson et al., 2006).

263 Regarding predictor variable importance, the most important variables were those that represented

264 hydrological regime (Source-of-flow) and flow discharge (Catchment area or Accumulated rainfall), with 
265

266

267

268

269

270

271

272

273

274

275

276

277

278

279

280

281

282

283

284

285

286

287

both variables representing segment scale (Frissell et al., 1986; Snelder \& Biggs, 2002). Large-scale predictor variables have more participation across models, and as the geographical scale of the variables decreases, their participation in the model does, as well; in addition, their importance is resolved species by species. This notion corresponds with the hierarchical framework of stream habitat proposed in the literature (Frissell et al., 1986; Snelder \& Biggs, 2002; Creque, Rutherford \& Zorn, 2005; Steen et al., 2008; Peredo-Parada et al., 2011).

\section{Records by fish species}

Although many authors mention the relationship between body size and data availability (Boone \& Krohn, 1999; McPherson \& Jetz, 2007; França \& Cabral, 2016), we found no studies in which this relationship was statistically evaluated. The premise that larger fish species are more detectable than smaller fish species depends on the sampling method and species characteristics (diurnal or nocturnal, color, habitat selection, etc.)(Boone \& Krohn, 1999). Thus, a detection bias may occur if sampling is conducted at the community or ensemble level using a single sampling methodology. However, if sampling is stratified or designed for a given species population using adequate methodologies, we would expect this bias to be corrected. In this study, presence information was obtained from a governmental database generated from published scientific studies, with sampling methodologies having been determined by studies focused on independently assessing species abundances and distributions. This situation explains the lack of relationship between fish size and presence records in our study.

\section{Fish size and model fit}

Our results regarding the body-size effects on SDM performanceare relevant to the unresolved debate about this expected theoretical relationship. While Morán-Ordóñez et al. (2017) found no significant relationship between body size and model performance for trees and birds, França \& Cabral (2016) 
288 successfully related model performance to species feeding mode and estuarine functional groups, with 289 body size having a marginally significant contribution to model performance. In studies aimed at river 290 fish, while Radinger et al. (2017) and Filipe, Cowx \& Collares-Pereira (2002) found that fish size increased 291 model performance, Markovic, Freyhof \& Wolter (2012) did not observe this pattern.

292 Our results show that the specificity performance metric increases with fish size, suggesting that the ability to predict true absences increases with fish size. This outcome means that models for smaller fishes tend to overpredict presences. These results reflect those of Lobo \& Tognelli (2011), who found using virtual species, models with randomly determined presences tend to have lower specificity relative to models with spatially biased presences. We suggest that in our study, smaller fish may have a statistically random distribution as a result of a potential mismatch between the study grain and their home range. This outcome would be the consequence of a random distribution of predictor variables used to characterize fish habitat (McPherson \& Jetz, 2007).

This finding has important implications for conservation and management. First, it suggests that the 301 environmental resolution used in the evaluation should be commensurate with the modeled species' home range. However, when this outcome is not possible (due to financial or logistic resources available, for example), then explicit assessment is necessary to detect any potential biases in model performance for species of different body sizes. In this way, it is also important to assess both metrics that represent general performance, such as AUC, TSS or Accuracy, and to include other specific metrics that may provide relevant information, such as any likelihood of overprediction of smaller species.

Our use of theoretical maximum length as the best available estimate of species body size does not necessarily reflect actual maximum body size in the study areas, and certainly may result in biases or estimation errors. Explicit assessment of possible biases stemming from the use of theoretical or 
311 improve our current understanding of the interaction between body size and SDM model performance.

312 This could be achieved by explicitly describing observed median and maximum body size of the set of 313 recorded presences within study hydrological basins, allowing body size to reflect current ecological

314 factors modifying this trait. Such a study design would allow the assessment of either fine scale habitat

315 alterations, or possible impacts of invasive species abundance. It must be noted that such a study is not

316 free of logistic and bioethical constraints. Most important, most of the fish species addressed in this

317 study face important threats, and wide scale sampling and individual monitoring may pose additional

318 stress to these individuals. As a result, an important source of data for such a study could be the samples

319 collected in the development of environmental impact assessment (EIA) studies. However, under

320 Chilean legislation, EIA sampling designs respond the project developer specific goals, and body size

321 sampling is not often included among the variables registered.

\section{Participation by predictor variable}

323 The predictor variables that show trends in model importance according to fish size are both obtained at 324 smaller scales (reach scale) (Frissell et al., 1986). The participation of riparian Vegetation and Within-

325 Channel Structures decreases with fish size, suggesting that these variables are not relevant to estimating the ecological niche of large fish species. For Within-Channel Structures, Radinger et al.

327 (2017) found that these may cause larger habitat reduction for larger fish species by creating stream barriers that limit their dispersal. This findingis consistent with our results, which show how the largest three species have low occurrence probabilities on reaches with almost one structure detected.

The relationship between riparian vegetation cover and fish size may be determined by the association

331 between riparian vegetation and river slope. Rivers with higher slopes have short alluvial plains that

332 allow for more riparian vegetation (Stefunkova, Neruda \& Vasekova, 2019). However, the morphologies 333 of Chilean fish species are not adapted to high-slope habitats(Arratia, 1987, 1992); therefore, we 
334 presume that riparian vegetation acts as a proxy of habitat conditions adequate for smaller species.

335 Functionally, this notion means that the occurrence probability of smaller species increases in rivers 336 with less riparian vegetation cover.

337 The current study presumed that no interspecific effects occurred between species that impacted SDMs, 338 particularly the potential role of the invasive species. Invasive species have been shown to influence 339 native fish body size (Blanchet et al., 2010), which can have significant effects on SDM performance. In 340 Chile, invasive species such as rainbow trout (Oncorhynchus mykiss) and brown trout (Salmo trutta) have 341 strong impacts on fishes (Pardo, Vila \& Capella, 2009; Arismendi et al., 2014) and may benefit from 342 riparian vegetation conservation, especially in upland areas (Lacy, Ugalde \& Mao, 2018). Regrettably, in 343 the current study, we were unable to evaluate the effect of invasive species on body size. Future studies 344 should seek to integrate ecological effects, especially effects caused by invasive species, into the 345 development of SDMs.

346 Finally, we want to highlight the use of source-of-flow as a predictor variable in our study; we have not

347 found this use in prior researchon river-species modeling, and it is especially important in torrential river 348 systems, such as those found in Chile. These systems have short runs, with relatively large lakes, glaciers, 349 or salt pans that significantly affect hydrological and hydraulic conditions. The source-of-flow variable is 350 implemented in river evaluations in New Zealand (Snelder \& Biggs, 2002) and Chile (Peredo-Parada et 351 al., 2011), which would facilitate its use in SDMs.

\section{CONCLUSIONS}

353 In this study, we found relationships between fish size and model performance, increasing specificity

354 along with fish size. This is new evidence in support of this classical theoretical relationship, supporting 355 the idea that model performance is affected by species characteristics. We also show how predictor 356 variables have different importance in the models, according to scale, with Source-of-Flow, Catchment 
357 area or Accumulated rainfall being relevant to all of the models, and Riparian Vegetation and Within-

358 Channel Structures being relevant variables according to the ecology of the species. Further

359 investigations should consider this potential source of bias to determine management and conservation

360 objectives from SDMs by either modifying the methodology or conducting a posteriori evaluations.

\section{REFERENCES}

362 Allouche O, Tsoar A, Kadmon R. 2006. Assessing the accuracy of species distribution models: prevalence,

363 kappa and the true skill statistic (TSS). Journal of Applied Ecology 43:1223-1232. DOI:

$364 \quad$ 10.1111/j.1365-2664.2006.01214.x.

365 Altman DG, Bland JM. 1994. Diagnostic tests. 1: Sensitivity and specificity. BMJ (Clinical research ed.)

$366 \quad 308: 1552$.

367 Arismendi I, Penaluna BE, Dunham JB, García de Leaniz C, Soto D, Fleming IA, Gomez-Uchida D, Gajardo

368 G, Vargas P V., León-Muñoz J, Gonzalo DG, Vargas P V., Leo J. 2014. Differential invasion success of 369 salmonids in southern Chile: Patterns and hypotheses. Reviews in Fish Biology and Fisheries 24:919-941. DOI: 10.1007/s11160-014-9351-0.

Arratia G. 1987. Description of the primitive family Diplomystidae (Siluriformes, Teleostei, Pisces): morphology, taxonomy, and phylogenetic implications. Zoologisches Forschungsinstitut und Museum Alexander Koenig.

Arratia G. 1992. Development and variation of the suspensorium of primitive catfishes (Teleostei: Ostariophysi) and their phylogenetic relationships. Zoologisches Forshungsinstitut und Museum Alexander Koenig.

Blanchet S, Grenouillet G, Beauchard O, Tedesco PA, Leprieur F, Dürr HH, Busson F, Oberdorff T, Brosse 

0248.2009.01432.x.

381

Boone RB, Krohn WB. 1999. Modeling the occurrence of bird species: are the errors predictable? Ecological Applications 9:835-848. DOI: 10.1890/1051-0761(1999)009[0835:MTOOBS]2.0.CO;2.

Brotons L, Thuiller W, Araújo MB, Hirzel AH. 2004. Presence-absence versus presence-only modelling methods for predicting bird habitat suitability. Ecography 27:437-448. DOI: 10.1111/j.09067590.2004.03764.x.

Cayuela L, Golicher D, Newton A, Kolb H, de Alburquerque FS, Arets EJM, Alkemade JRM, Pérez AM. 2009. Species distribution modeling in the tropics: problems, potentialities, and the role of biological data for effective species conservation. Tropical Conservation Science 2:319-352.

Chambers JM. 1992. Linear models. In: Chambers JM, Hastie TJ eds. Statistical models in S. Routledge, 95-144.

Creque SM, Rutherford ES, Zorn TG. 2005. Use of GIS-Derived Landscape-Scale Habitat Features to Explain Spatial Patterns of Fish Density in Michigan Rivers. North American Journal of Fisheries Management 25:1411-1425. DOI: 10.1577/M04-121.1.

Cribari-Neto F, Zeileis A. 2010. Beta Regression in R. Journal of Statistical Software 34:1-24. DOI: 10.18637/jss.v034.i02.

Das KR, Imon A. 2016. A brief review of tests for normality. American Journal of Theoretical and Applied Statistics 5:5-12.

Elith J, Leathwick JR. 2009. Species Distribution Models: Ecological Explanation and Prediction Across Space and Time. Annual Review of Ecology, Evolution, and Systematics 40:677-697. DOI: 10.1146/annurev.ecolsys.110308.120159. 
401 Errázuriz K. AM, Cereceda T. P, Gonzalez L. JI, Gonzalez L. M, Henriquez R. M, Rioseco H. R. 1998. Manual 402 de geografía de Chile. Editorial Andrés Bello.

403

404

405

406

407

408

409

410

411

412

413

414

415

416

417

418

419

420

421

ESRI. 2010. ArcGIS Desktop.

França S, Cabral HN. 2016. Predicting fish species distribution in estuaries: Influence of species' ecology in model accuracy. Estuarine, Coastal and Shelf Science 180:11-20. DOI: 10.1016/j.ecss.2016.06.010.

Frissell CA, Liss WJ, Warren CE, Hurley MD. 1986. A hierarchical framework for stream habitat classification: Viewing streams in a watershed context. Environmental Management 10:199-214. DOI: $10.1007 / B F 01867358$.

Gevrey M, Dimopoulos I, Lek S. 2003. Review and comparison of methods to study the contribution of variables in artificial neural network models. In: Ecological Modelling. DOI: 10.1016/S03043800(02)00257-0.

Google inc. 2009. Google Earth.

Guisan A, Thuiller W. 2005. Predicting species distribution: offering more than simple habitat models. Ecology Letters 8:993-1009. DOI: 10.1111/j.1461-0248.2005.00792.x.

Habit E, Dyer B, Vila I. 2006. Estado de conocimiento de los peces dulceacuícolas de Chile. Gayana (Concepción) 70:100-113. DOI: 10.4067/S0717-65382006000100016.

Imon AHMR. 2003. Regression residuals, moments, and their use in tests for normality. Communications in Statistics - Theory and Methods. DOI: 10.1081/STA-120019960.

Kozak M, Piepho H-P. 2018. What's normal anyway? Residual plots are more telling than significance tests when checking ANOVA assumptions. Journal of Agronomy and Crop Science 204:86-98. DOI: 
423 Kuhn M. 2008. Building Predictive Models in R Using the caret Package. Journal of Statistical Software 28:1-26. DOI: 10.18637/jss.v028.i05.

425

426

427

428

429

430

431

432

433

434

435

436

437

438

439

440

441

442

443

Lacy SN, Ugalde F, Mao L. 2018. Invasive Rainbow Trout (Oncorhynchus mykiss) Are Not Affected by Different Land Uses in a Multi-Use, Mediterranean Climate Landscape. Fishes 3:37. DOI: 10.3390/fishes3040037.

Lobo JM, Tognelli MF. 2011. Exploring the effects of quantity and location of pseudo-absences and sampling biases on the performance of distribution models with limited point occurrence data. Journal for Nature Conservation 19:1-7. DOI: 10.1016/J.JNC.2010.03.002.

Manel S, Dias JM, Ormerod SJ. 1999. Comparing discriminant analysis, neural networks and logistic regression for predicting species distributions: A case study with a Himalayan river bird. Ecological Modelling 120:337-347. DOI: 10.1016/S0304-3800(99)00113-1.

Mastrorillo S, Lek S, Dauba F, Belaud A. 1997. The use of artificial neural networks to predict the presence of small-bodied fish in a river. Freshwater Biology 38:237-246. DOI: 10.1046/j.13652427.1997.00209.x.

McPherson JM, Jetz W. 2007. Effects of species' ecology on the accuracy of distribution models. Ecography 30:135-151. DOI: 10.1111/j.0906-7590.2007.04823.x.

Ministerio de Energía -División de Desarrollo Sustentable. 2016. Estudio de Cuencas. Análisis de las Condicionantes para el Desarrollo Hidroeléctrico en las Cuencas del Maule, Biobío, Toltén, Valdivia, Bueno, Puelo, Yelcho, Palena, Cisnes, Aysén, Baker y Pascua. Santiago: Gobierno de Chile.

Morán-Ordóñez A, Lahoz-Monfort JJ, Elith J, Wintle BA. 2017. Evaluating 318 continental-scale species distribution models over a 60-year prediction horizon: what factors influence the reliability of 
predictions? Global Ecology and Biogeography 26:371-384. DOI: 10.1111/geb.12545.

445

446

447

448

449

450

451

452

453

454

455

456

457

458

459

460

461

462

463

464

Pardo R, Vila I, Capella JJ. 2009. Competitive interaction between introduced rainbow trout and native silverside in a Chilean stream. Environmental Biology of Fishes. DOI: 10.1007/s10641-009-9532-1.

Pearson RG, Raxworthy CJ, Nakamura M, Townsend Peterson A. 2006. Predicting species distributions from small numbers of occurrence records: a test case using cryptic geckos in Madagascar. Journal of Biogeography 34:102-117. DOI: 10.1111/j.1365-2699.2006.01594.x.

Peredo-Parada M, Martínez-Capel F, Quevedo DI, Hernández-Mascarell AB. 2011. Implementación de una clasificación eco-hidrológica para los ríos de Chile. Gayana (Concepción) 75:26-38. DOI: 10.4067/S0717-65382011000100003.

Perry AL, Low PJ, Ellis JR, Reynolds JD. 2005. Climate change and distribution shifts in marine fishes. Science (New York, N.Y.) 308:1912-5. DOI: 10.1126/science.1111322.

R Core Team. 2017. R: A language and environment for statistical computing. Vienna, Austria: R Foundation for Statistical Computing; 2014.

Radinger J, Essl F, Hölker F, Horký P, Slavík O, Wolter C. 2017. The future distribution of river fish: The complex interplay of climate and land use changes, species dispersal and movement barriers. Global Change Biology 23:4970-4986. DOI: 10.1111/gcb.13760.

Radinger J, Wolter C. 2015. Disentangling the effects of habitat suitability, dispersal, and fragmentation on the distribution of river fishes. Ecological Applications 25:914-927. DOI: 10.1890/14-0422.1.

Rana MS, Midi H, Imon A. 2009. A robust rescaled moment test for normality in regression. Journal of Mathematics and Statistics 5:54.

Segurado P, Araújo MB. 2004. An evaluation of methods for modelling species distributions. Journal of 
Biogeography 31:1555-1568. DOI: 10.1111/j.1365-2699.2004.01076.x.

466 Snelder TH, Biggs BJF. 2002. MULTISCALE RIVER ENVIRONMENT CLASSIFICATION FOR WATER RESOURCES MANAGEMENT. Journal of the American Water Resources Association 38:1225-1239. DOI: $10.1111 / \mathrm{j} .1752-1688.2002 . t b 04344 . x$.

469

470

471

472

473

474

475

476

477 478

Steen PJ, Zorn TG, Seelbach PW, Schaeffer JS. 2008. Classification Tree Models for Predicting Distributions of Michigan Stream Fish from Landscape Variables. Transactions of the American Fisheries Society 137:976-996. DOI: 10.1577/T07-119.1.

Stefunkova Z, Neruda M, Vasekova B. 2019. Impact Evaluation of Riparian Vegetation on Aquatic Habitat Quality of Rivers. IOP Conference Series: Earth and Environmental Science 221:012111. DOI: 10.1088/1755-1315/221/1/012111.

Stern HS. 1996. Neural Networks in Applied Statistics. Technometrics 38:205-214. DOI: 10.1080/00401706.1996.10484497.

Stockwell DR., Peterson AT. 2002. Effects of sample size on accuracy of species distribution models. Ecological Modelling 148:1-13. DOI: 10.1016/S0304-3800(01)00388-X.

Suarez-Seoane S, Osborne PE, Alonso JC. 2002. Large-scale habitat selection by agricultural steppe birds in Spain: identifying species-habitat responses using generalized additive models. Journal of Applied Ecology 39:755-771. DOI: 10.1046/j.1365-2664.2002.00751.x.

Velez DR, White BC, Motsinger AA, Bush WS, Ritchie MD, Williams SM, Moore JH. 2007. A balanced accuracy function for epistasis modeling in imbalanced datasets using multifactor dimensionality reduction. Genetic Epidemiology 31:306-315. DOI: 10.1002/gepi.20211.

Vila I, Fuentes L, Contreras M. 1999. Peces límnicos de Chile. Boletín del Museo Nacronal de Historia Natural. Chile 48:61-75. 
487 Vila I, Pardo R, Dyer B, Habit E. 2006. Peces límnicos: diversidad, origen y estado de conservación. In:

488 Vila I, Veloso A, Schlatter R, Ramírez C eds. Macrófitas y vertebrados de los sistemas límnicos de $489 \quad$ Chile. Editorial Universitaria, 186. 
Figure 1

Study area

Map shows study basins (Valdivia and Bueno). Green river reaches contain species records.

The black square in the map of South America shows the study area.

100000.000

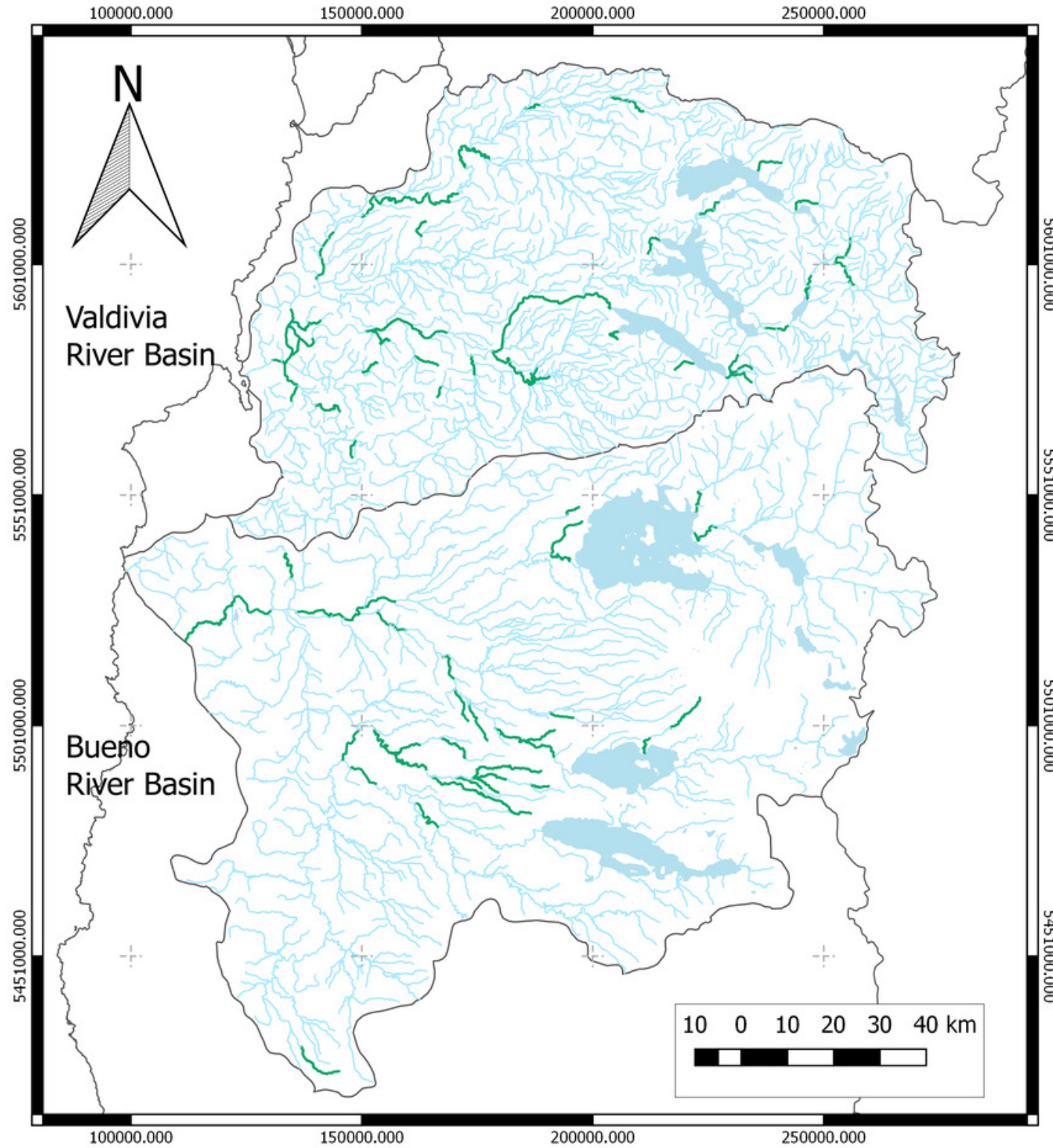

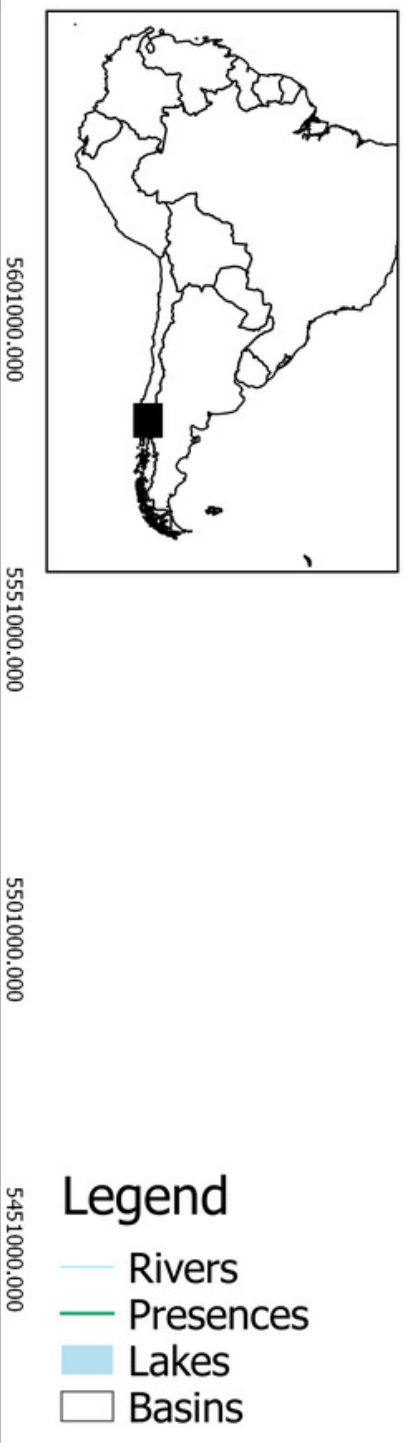


Figure 2

Significant relationships between SDM metrics and (Ln) fish size

A) Positive relationship between the specificity of the SDM and Ln fish size. B) Negative relationship between importance in the SDM of Within-Channel Structures and Ln fish size. C) Negative relationship between importance in the SDM of Riparian Vegetation and Ln fish size.

Text in each plot shows pseudo $\mathrm{R}^{2}$ and $\mathrm{p}$-value obtain with beta regression analysis.
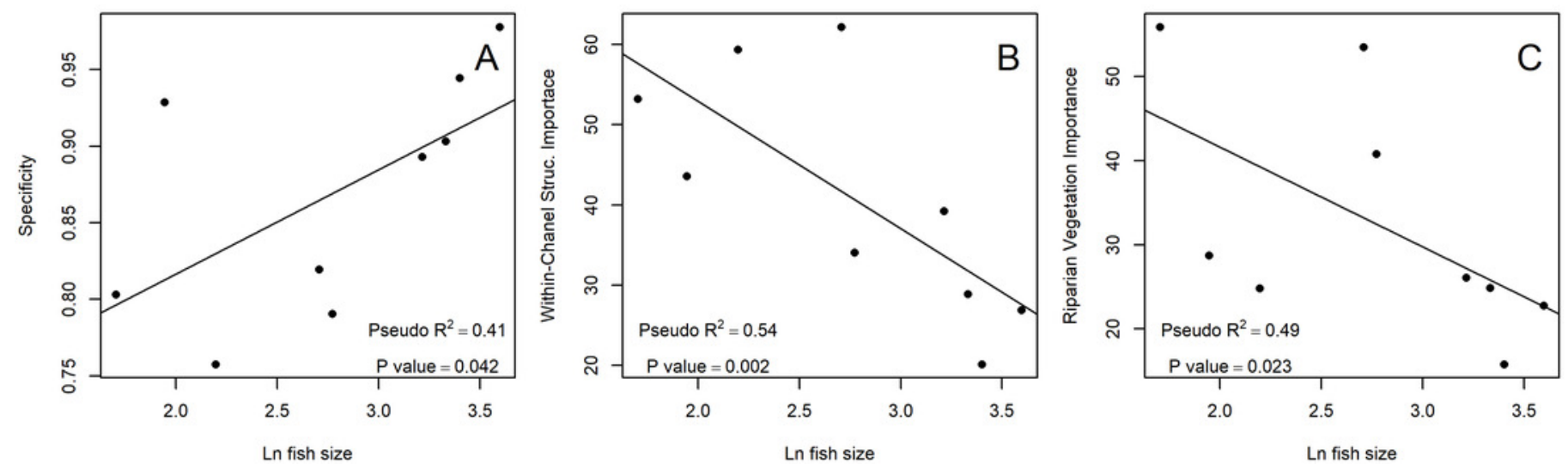


\section{Figure 3}

Occurrence probability boxplot according to species and predictor variable class

A) Reaches were classified as $1=100 \%$ riparian vegetation and $0<100 \%$ riparian

vegetation. B) Reaches were classified as $1=$ one or more within-channel structures and $0=$ no within-channel structures. Boxplots show the occurrence probability of each species model by reach class. Species on the $\mathrm{X}$ axis are sorted by size, with larger species on the right. Boxplot is represent by five values:the extreme of the lower whisker isthe lowest datum still within 1.5 Interquartile range, the lower box extreme is the first quartile,the middle line is the median, the upper box extreme is the third quartile andthe extreme of the upper whisker is the highest datum still within 1.5 Interquartile range. Outliers are excluded to clarify visualization. 

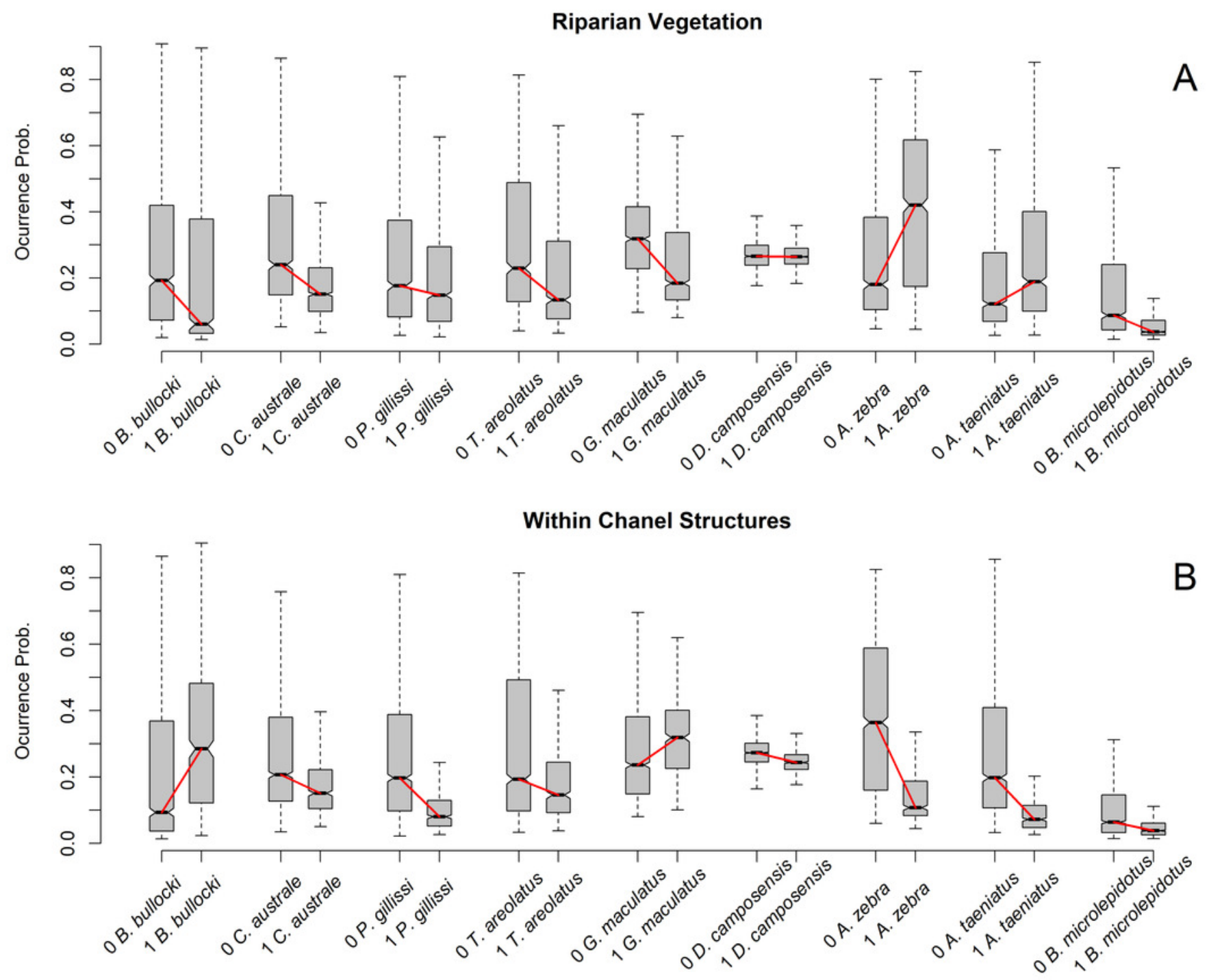


\section{Table $\mathbf{1}$ (on next page)}

Model summaries

Columns on order: Modeled species, natural log of maximum body size in $\mathrm{cm}$, conservation category assigned by the Chilean government, number of recorded presences, $\mathrm{K}$ folds used in the model, number of modeled presences, and TSS, AUC, Balanced accuracy (B ACC), Sensibility (Sens) and Specificity (Spec) values for each model with their standard errors (SE). 


\begin{tabular}{|c|c|c|c|c|c|c|c|c|c|c|c|c|c|c|c|}
\hline Species & Ln size & $\begin{array}{l}\text { Conservation } \\
\text { category }\end{array}$ & Presences & $\begin{array}{l}\mathrm{K} \text { folds } \\
\text { by } \\
\text { model }\end{array}$ & $\begin{array}{l}\text { Presences } \\
\text { used on } \\
\text { model }\end{array}$ & TSS & $\begin{array}{l}\text { TSS } \\
\text { SE }\end{array}$ & AUC & $\begin{array}{l}\text { AUC } \\
\text { SE }\end{array}$ & $\begin{array}{l}\text { B } \\
\text { Acc }\end{array}$ & $\begin{array}{l}\text { B } \\
\text { Acc } \\
\text { SE }\end{array}$ & Sens & $\begin{array}{l}\text { Sens } \\
\text { SE }\end{array}$ & Spec & $\begin{array}{l}\text { Spec } \\
\text { SE }\end{array}$ \\
\hline Aplochitontaeniatus $^{1}$ & 3.40 & EN & 28 & 3 & 17 & 0.78 & 0.03 & 0.92 & 0.03 & 0.89 & 0.02 & 0.83 & 0.06 & 0.94 & 0.03 \\
\hline Aplochiton zebra ${ }^{2}$ & 3.33 & EN & 22 & 3 & 16 & 0.47 & 0.05 & 0.87 & 0.02 & 0.73 & 0.03 & 0.57 & 0.02 & 0.90 & 0.03 \\
\hline $\begin{array}{l}\text { Basilichthys } \\
\text { microlepidotus }\end{array}$ & 3.60 & FP & 56 & 3 & 23 & 0.83 & 0.08 & 0.98 & 0.01 & 0.92 & 0.04 & 0.86 & 0.08 & 0.98 & 0.01 \\
\hline BrachygalaxiasBullocki ${ }^{4}$ & 1.70 & VU & 37 & 3 & 28 & 0.45 & 0.05 & 0.84 & 0.01 & 0.72 & 0.03 & 0.64 & 0.08 & 0.80 & 0.03 \\
\hline Cheirodonaustrale 5 & 1.95 & VU & 56 & 3 & 21 & 0.74 & 0.04 & 0.94 & 0.01 & 0.87 & 0.02 & 0.81 & 0.05 & 0.93 & 0.02 \\
\hline Diplomystescamposensis $^{6}$ & 3.21 & EN & 34 & 2 & 14 & 0.68 & 0.18 & 0.90 & 0.07 & 0.84 & 0.09 & 0.79 & 0.15 & 0.89 & 0.03 \\
\hline Galaxias maculatus $^{7}$ & 2.77 & FP & 30 & 3 & 17 & 0.55 & 0.01 & 0.92 & 0.00 & 0.77 & 0.00 & 0.76 & 0.07 & 0.79 & 0.07 \\
\hline Perciliagillissi ${ }^{8}$ & 2.20 & EN & 62 & 3 & 33 & 0.55 & 0.06 & 0.87 & 0.03 & 0.77 & 0.03 & 0.79 & 0.08 & 0.76 & 0.06 \\
\hline Trichomycterusareolatus $^{9}$ & 2.71 & VU & 72 & 3 & 36 & 0.46 & 0.01 & 0.82 & 0.01 & 0.73 & 0.01 & 0.64 & 0.03 & 0.82 & 0.03 \\
\hline
\end{tabular}

1 Table 1. Model summaries. Columns on order: Modeled species, natural log of maximum body size in cm, conservation category assigned by the Chilean government, number of recorded presences, $\mathrm{K}$ folds used in the model, number of modeled presences, and TSS, AUC, Balanced accuracy (B Acc), Sensibility (Sens) and Specificity (Spec) values for each model with their standard errors (SE).

Reference to fish size:

${ }^{1}$ Ministerio del Medio Ambiente (2011a)

${ }^{2}$ Ministerio del Medio Ambiente (2011b)

${ }^{3}$ Cifuentes et al. (2012)

${ }^{4}$ Ministerio del Medio Ambiente (2008d)

${ }^{5}$ Ministerio del Medio Ambiente (2008a)

${ }^{6}$ Ministerio del Medio Ambiente (2008e)

${ }^{7}$ Ministerio del Medio Ambiente (2008b)

${ }^{8}$ Froese \& Pauly (2017) 
${ }^{9}$ Ministerio del Medio Ambiente (2008c) 


\section{Table 2 (on next page)}

Results of analyses of different response variables as a function of fish size

Columns in order: response variables, $p$-value of the Phi coefficient, $p$-value of the RMtest to residuals, evaluation of the presence of a significant covariance (True or False), pseudo $\mathrm{R}^{2}$ (with link transformation of response variable), mean estimate of analysis, Std. Error of analysis, and the Z-value and P-value of the beta regression analysis. 
1 Table 2. Results of analyses of different response variables as a function of fish size. Columns in order: response variables, $p$-value of the Phi

2 coefficient, $p$-value of the RMtest to residuals, evaluation of the presence of a significant covariance (True or False), pseudo $R^{2}$ (with link

3 transformation of response variable), mean estimate of analysis, Std. Error of analysis, and the Z-value and P-value of the beta regression

4 analysis.

\begin{tabular}{|c|c|c|c|c|c|c|c|c|c|}
\hline Response variables & \begin{tabular}{|l|} 
Phi \\
coefficient \\
p-value \\
\end{tabular} & $\begin{array}{l}\text { RMtest } p \\
\text { value }\end{array}$ & $\begin{array}{l}\text { Significant } \\
\text { covariance }\end{array}$ & Pseudo $\mathrm{R}^{2}$ & $\begin{array}{l}\text { Mean } \\
\text { estimate }\end{array}$ & Std. Error & $Z$ value & $P$ value & Significance \\
\hline Balanced accuracy & 0.03 & 0.68 & $\mathrm{~F}$ & 0.26 & 0.31 & 0.21 & 1.51 & 0.132 & \\
\hline Sensitivity & 0.03 & 0.70 & $\mathrm{~F}$ & 0.10 & 0.16 & 0.23 & 0.70 & 0.484 & \\
\hline Specificity & 0.03 & 0.40 & $\mathrm{~F}$ & 0.41 & 0.56 & 0.28 & 2.04 & 0.042 & $* *$ \\
\hline TSS & 0.03 & 0.68 & $\mathrm{~F}$ & 0.26 & 0.31 & 0.21 & 1.51 & 0.132 & \\
\hline AUC & 0.03 & 0.48 & $\mathrm{~F}$ & 0.48 & 0.36 & 0.23 & 1.57 & 0.117 & \\
\hline Cross-channel structure & 0.03 & 0.19 & $\mathrm{~F}$ & 0.11 & -0.21 & 0.25 & -0.82 & 0.411 & \\
\hline $\begin{array}{l}\text { Within-channel } \\
\text { structure }\end{array}$ & 0.03 & 0.47 & $\mathrm{~F}$ & 0.54 & -0.65 & 0.21 & -3.15 & 0.002 & $* * *$ \\
\hline Land use: Antr-Antr & 0.02 & 0.38 & $\mathrm{~F}$ & 0.21 & -0.13 & 0.54 & -0.24 & 0.813 & \\
\hline Land use: Nat-Antr & 0.03 & 0.20 & $\mathrm{~F}$ & 0.39 & -0.52 & 0.49 & -1.07 & 0.283 & \\
\hline Land use: Nat-Nat & 0.03 & 0.27 & $\mathrm{~F}$ & 0.31 & -0.26 & 0.29 & -0.92 & 0.358 & \\
\hline Altitude & 0.02 & 0.29 & $\mathrm{~F}$ & 0.12 & -0.41 & 0.38 & -1.09 & 0.277 & \\
\hline Slope & 0.02 & 0.36 & $\mathrm{~F}$ & 0.04 & -0.21 & 0.42 & -0.50 & 0.616 & \\
\hline Channel width & 0.02 & 0.99 & $\mathrm{~F}$ & 0.15 & 0.36 & 0.44 & 0.80 & 0.423 & \\
\hline Riparian vegetation & 0.03 & 0.49 & $\mathrm{~F}$ & 0.49 & -0.50 & 0.22 & -2.27 & 0.023 & $* *$ \\
\hline Catchment area & 0.02 & 0.61 & $\mathrm{~F}$ & 0.15 & -0.51 & 0.60 & -0.85 & 0.397 & \\
\hline Annual rainfall & 0.02 & 0.49 & $\mathrm{~T}$ & 0.47 & 0.31 & 0.46 & 0.66 & 0.508 & \\
\hline Source-of-flow: Lakes & 0.03 & 0.68 & $\mathrm{~F}$ & 0.25 & -0.47 & 0.33 & -1.41 & 0.158 & \\
\hline $\begin{array}{l}\text { Source-of-flow: } \\
\text { Foodplain }\end{array}$ & 0.03 & 0.30 & $\mathrm{~F}$ & 0.03 & 0.19 & 0.44 & 0.44 & 0.659 & \\
\hline
\end{tabular}




\begin{tabular}{|l|l|l|l|l|l|l|l|l|l|}
\hline $\begin{array}{l}\text { Source-of-flow: } \\
\text { Mountains }\end{array}$ & 0.03 & 0.01 & F & 0.26 & -0.27 & 0.33 & -0.81 & 0.420 \\
\hline Source-of-flow: Valleys & 0.03 & 0.74 & F & 0.25 & -0.53 & 0.33 & -1.62 & 0.106 & \\
\hline
\end{tabular}




\section{Table 3(on next page)}

Variable participation by modeled species

Bold values indicate the largest values by species. Final row represents the participation mean by variable. 
1 Table 3a. Variable participation by modeled species. Bold values indicate the largest values by species. Final row represents the participation mean

2 by variable.

\begin{tabular}{|c|c|c|c|c|c|c|c|c|c|}
\hline Species & \begin{tabular}{|l} 
Within- \\
channel \\
structures \\
\end{tabular} & \begin{tabular}{|l|} 
Cross- \\
channel \\
structures \\
\end{tabular} & $\begin{array}{l}\text { Land use: } \\
\text { Antr-Antr }\end{array}$ & $\begin{array}{l}\text { Land use: } \\
\text { Nat-Antr }\end{array}$ & $\begin{array}{l}\text { Land use: } \\
\text { Nat-Nat }\end{array}$ & Land use: All & Altitude & Slope & $\begin{array}{l}\text { Channel } \\
\text { width }\end{array}$ \\
\hline $\begin{array}{l}\text { Aplochiton } \\
\text { taeniatus }\end{array}$ & 25.40 & 20.11 & 10.63 & 2.73 & 13.60 & 26.96 & 48.39 & 17.09 & 58.79 \\
\hline Aplochiton zebra & 32.84 & 28.87 & 13.85 & 5.12 & 16.49 & 35.47 & 14.14 & 66.58 & 95.34 \\
\hline $\begin{array}{l}\text { Basilichthys } \\
\text { australis }\end{array}$ & 16.08 & 26.85 & 6.01 & 3.84 & 3.60 & 13.45 & 37.40 & 9.62 & 67.91 \\
\hline $\begin{array}{l}\text { Brachygalaxias } \\
\text { bullocki }\end{array}$ & 35.48 & 53.20 & 23.58 & 27.80 & 29.32 & 80.70 & 24.02 & 34.48 & 50.85 \\
\hline $\begin{array}{l}\text { Cheirodon } \\
\text { australe }\end{array}$ & 20.30 & 43.59 & 14.01 & 11.19 & 15.57 & 40.76 & 63.42 & 51.03 & 57.85 \\
\hline $\begin{array}{l}\text { Diplomystes } \\
\text { camposensis }\end{array}$ & 19.88 & 39.20 & 28.79 & 13.95 & 34.79 & 77.53 & 34.61 & 32.04 & 75.77 \\
\hline $\begin{array}{l}\text { Galaxias } \\
\text { maculatus }\end{array}$ & 57.51 & 34.04 & 97.22 & 87.72 & 13.65 & 198.59 & 59.40 & 68.30 & 35.27 \\
\hline Percilia gillissi & 33.63 & 59.36 & 6.00 & 12.40 & 8.67 & 27.07 & 81.60 & 11.84 & 79.45 \\
\hline $\begin{array}{l}\text { Trichomycterus } \\
\text { areolatus }\end{array}$ & 26.79 & 62.18 & 20.75 & 24.51 & 15.50 & 60.76 & 47.99 & 39.15 & 99.26 \\
\hline $\begin{array}{l}\text { Summary } \\
\text { participation }\end{array}$ & 26.79 & 40.82 & 24.54 & 21.03 & 16.80 & 62.37 & 45.66 & 36.68 & 68.94 \\
\hline
\end{tabular}

3

4 
8 Table 3b. Variable participation by modeled species. Bold values indicate the largest values by species. Final row represents the participation mean

9 by variable.

\begin{tabular}{|l|r|r|r|r|r|r|r|r|}
\hline sp & Riparian & Catchment & $\begin{array}{l}\text { Annual } \\
\text { rainfall }\end{array}$ & $\begin{array}{l}\text { Source-of- } \\
\text { areatlow: Lakes }\end{array}$ & $\begin{array}{l}\text { Source-of- } \\
\text { flow: Plain }\end{array}$ & $\begin{array}{l}\text { Source-of- } \\
\text { flow: } \\
\text { Mountains }\end{array}$ & $\begin{array}{l}\text { Source-of- } \\
\text { flow: } \\
\text { Valleys }\end{array}$ & $\begin{array}{l}\text { Source-of- } \\
\text { flow: All }\end{array}$ \\
\hline Aplochiton taeniatus & 15.77 & 30.88 & $\mathbf{1 0 0 . 0 0}$ & 9.39 & 14.93 & 28.50 & 37.39 & 90.21 \\
\hline Aplochiton zebra & 24.83 & 18.12 & 77.49 & 20.14 & 21.10 & 29.33 & 25.62 & 96.19 \\
\hline Basilichthys australis & 22.75 & $\mathbf{9 4 . 5 0}$ & 8.12 & 11.10 & 8.31 & 2.94 & 4.78 & 27.13 \\
\hline Brachygalaxias bullocki & 55.88 & $\mathbf{9 9 . 3 8}$ & 40.38 & 30.21 & 33.43 & 16.29 & 27.18 & 107.11 \\
\hline Cheirodon australe & 28.69 & $\mathbf{1 0 0 . 0 0}$ & 26.50 & 24.72 & 1.18 & 30.24 & 43.95 & 100.09 \\
\hline $\begin{array}{l}\text { Diplomystes } \\
\text { camposensis }\end{array}$ & 26.05 & $\mathbf{1 0 0 . 0 0}$ & 31.62 & 30.51 & 15.45 & 37.68 & 6.94 & 90.57 \\
\hline Galaxias maculatus & 40.79 & 31.67 & 33.86 & 62.37 & 23.40 & 51.51 & 30.35 & 167.63 \\
\hline Percilia gillissi & 24.77 & 39.48 & 75.92 & 43.56 & 7.01 & 42.01 & 19.98 & 112.56 \\
\hline $\begin{array}{l}\text { Trichomycterus } \\
\text { areolatus }\end{array}$ & 53.47 & 59.72 & 34.26 & 16.63 & 54.65 & 31.11 & 39.94 & 142.33 \\
\hline Summary participation & 32.56 & $\mathbf{6 3 . 7 5}$ & 47.57 & 27.63 & 19.94 & 29.96 & 26.24 & 103.76 \\
\hline
\end{tabular}

